\title{
Determination of Mycobacterial Phylogeny on the Basis of Immunological Relatedness of Superoxide Dismutases
}

\author{
C. T. SHIVANNAVAR, ${ }^{1}$ V. M. KATOCH,${ }^{1 *}$ V. D. SHARMA, ${ }^{1}$ M. A. PATIL, ${ }^{1}$ K. KATOCH, ${ }^{1}$ \\ V. P. BHARADWAJ, ${ }^{1}$ R. K. SHARMA, ${ }^{1}$ A. S. BHATIA, ${ }^{1}$ AND B. M. AGRAWAL ${ }^{2}$ \\ Central JALMA Institute for Leprosy (ICMR), Agra 282001, ${ }^{1}$ \\ and S. N. Medical College, Agra, ${ }^{2}$ India
}

\begin{abstract}
Sixteen strains of cultivable mycobacteria were grown in Sauton's medium, and Mycobacterium leprae was purified from armadillo liver. Cell extracts were prepared from log-phase growths of each of the cultivable mycobacterial strains. Superoxide dismutase (SOD) enzyme was purified from all cultivable mycobacterial strains included in the study, and antibodies against purified SOD enzyme were raised in rabbits. Immunological distances (ImDs) between these anti-SOD antibodies and SOD antigens were determined by a previously described immunoprecipitation method and by a recently developed enzyme-linked immunosorbent assay (ELISA) technique. The reciprocal ImDs among mycobacterial strains were constant, reproducible and consistent by these two methods. An evolutionary tree was constructed on the basis of estimated ImDs. Except for $M$. duvalii and $M$. terrae, slowly and rapidly growing mycobacterial species appeared to be separately grouped by this analysis. Rapid growers clustered into a group which is near that of some slow-growing mycobacteria. $M$. avium falls almost in the middle of the evolutionary tree and the position of $M$. leprae was found to be between those of $M$. avium and $M$. bovis BCG. Measurement of immunological relatedness of SODs provides an alternative system with which to study the taxonomical relatedness among mycobacteria.
\end{abstract}

Among the bacteria pathogenic to humans, the genus Mycobacterium stands out prominently. Apart from those mycobacteria causing tuberculosis, the nontuberculous mycobacteria have recently attracted attention. First, wherever tuberculosis has declined, they now account for a greater proportion of cases of mycobacterial diseases. Second, like tuberculosis they have emerged as common secondary pathogens among AIDS patients. In addition to being pathogenic in humans, several mycobacterial species have been established as pathogens in animals. Besides the cultivable pathogenic mycobacterial species, noncultivable species like $M$. leprae and others (7) pose special identification problems. Specific identification of any newly isolated mycobacterium would thus be of great interest to clinicians, epidemiologists, microbiologists, and taxonomists.

The identification and classification of mycobacteria has been done by conventional, time-consuming biochemical tests (43-45) followed by serotyping (32), lipid analysis (24), bacteriophage typing (29), and bacteriocin typing (41). Besides the recently described molecular biological techniques such as restriction fragment length polymorphism analysis using ribosomal and nonribosomal RNA and/or DNA probes and hybridization with specific probes $(12,23)$, another approach is antigenic analysis, which may involve studies of either overall resemblances and/or diversity of antigenic profiles (37) or relationships of any single enzyme or protein (3). In earlier studies on mycobacteria, catalase was chosen as a target molecule for the measurement of immunological relatedness and/or divergences $(46,47)$, and the system generated was found to be applicable to diverse mycobacteria, including hostgrown mycobacterial species such as $M$. lepraemurium (14). As $M$. leprae was found to possess very low specific catalase activity, there was a need to select an alternate target molecule(s) (15). In the present study, superoxide dismutase (SOD) was chosen as an antigenic marker because SOD is universally present in sufficient quantities in all mycobacteria investigated

* Corresponding author. Mailing address: Central JALMA Institute for Leprosy, Post Box 101, Taj Ganj, Agra 282001, India. so far, including $M$. leprae $(2,10,13,18,19,22,48)$. Further preliminary studies indicated the potential of this approach (13). This communication describes an approach based on the immunological distances (ImDs) of SOD molecules.

\section{MATERIALS AND METHODS}

Bacterial strains. Seventeen mycobacterial strains included in this study are listed in Table 1 . All cultivable type strains obtained were originally obtained from J. Stanford (London, United Kingdom), the National Institutes of Health (Bethesda, Md.), and Central Drug Research Institute (Lucknow, India) and have been maintained in our laboratory. $M$. leprae was purified from infected armadillo liver and spleen.

All cultivable mycobacterial strains were first grown in Loewenstein Jensen medium (20). The primary cultures on Loewenstein Jensen medium were subsequently subcultured in liquid Sauton's medium (31) to obtain sufficient growth. The log-phase cultures of slowly and rapidly growing mycobacteria were collected after 20 days (static growth) plus 10 days (shaken growth) and after 7 days (static growth) and 4 days (shaken growth), respectively. Cells were centrifuged at $8,000 \times \mathrm{g}$, washed with phosphate buffer $(0.01 \mathrm{M}, \mathrm{pH} 7.2)$, and stored at $-20^{\circ} \mathrm{C}$ until used. $M$. leprae bacilli were purified from infected armadillo liver and spleen by the protocol of Draper (6).

Detailed protocols for preparation of cell extracts (CEs), purification of SODs, measurement of SOD activity, raising of antibodies, measurement of immunological relatedness by immunoprecipitation (13), and development of enzymelinked immunosorbent assay (ELISA) are being published elsewhere (34).

Preparation of CEs. The log-phase cells of each mycobacterial strain were suspended in $0.01 \mathrm{M}$ phosphate buffer ( $\mathrm{pH} \mathrm{7.8)}$ at the ratio of 1:10 (wt/vol). The suspensions were prechilled and lysed by passage through a French pressure cell press (SLM Instruments, Inc., Urbana, Ill.) at a pressure of $28,000 \mathrm{lb} / \mathrm{in}^{2}$. The lysates were centrifuged at $12,000 \times g$ for $45 \mathrm{~min}$ at $4^{\circ} \mathrm{C}$ to obtain clear $\mathrm{CE}$, and aliquots were stored at $-70^{\circ} \mathrm{C}$. Major parts of CEs were used for the purification of SOD enzyme. To obtain CE of $M$. leprae, $4 \mathrm{ml}$ of the cell suspension was passed through a mini French pressure cell press and the $\mathrm{CE}$ was directly used for immunoassays.

Purification of SOD enzymes from CEs. SODs from CEs from various cultivable mycobacteria were purified by a slight modification of previously described techniques $(16,18)$. The fraction containing SOD was precipitated by sequential treatment of $\mathrm{CEs}$ with $\mathrm{KCl}$, streptomycin sulfate, and ammonium sulfate. The precipitate was separated by centrifugation and dissolved in a minimum volume of $0.01 \mathrm{M}$ phosphate buffer ( $\mathrm{pH} 7.2$ ). The suspension was dialyzed against 2 liters of $0.1 \mathrm{M}$ phosphate buffer ( $\mathrm{pH} 7.2$ ) overnight with two changes of buffer and finally with $0.01 \mathrm{M}$ phosphate buffer $\left(\mathrm{pH} 7.2\right.$ ) at $4^{\circ} \mathrm{C}$. Finally, the SOD was purified by polyacrylamide gel electrophoresis (PAGE) (by both diffusion and electroelution of SOD bands from the gels) until a single protein band on a $10 \%$ PAGE gel corresponding to a single achromatic SOD band on the gel was obtained. The eluted enzyme was concentrated by $50 \%$ polyethylene glycol (PEG) 6000, thus ensuring minimum exposure of the enzyme to room temper- 
TABLE 1. List of mycobacterial strains included in this study

\begin{tabular}{|c|c|}
\hline Species & Source/type reference \\
\hline \multicolumn{2}{|c|}{ 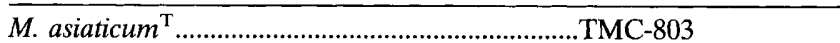 } \\
\hline \multicolumn{2}{|c|}{ 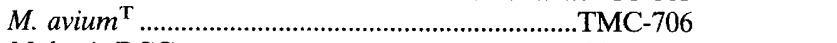 } \\
\hline \multicolumn{2}{|c|}{ 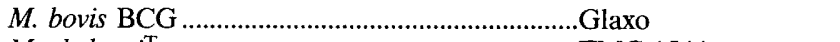 } \\
\hline \multicolumn{2}{|c|}{ 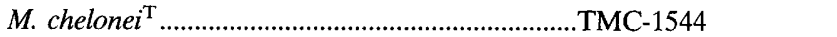 } \\
\hline \multicolumn{2}{|c|}{ 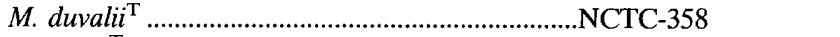 } \\
\hline \multicolumn{2}{|c|}{ 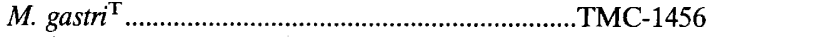 } \\
\hline \multicolumn{2}{|c|}{ M. kansasii ............................................................. 8} \\
\hline \multicolumn{2}{|l|}{ M. phlei ${ }^{\mathrm{T}} \ldots \ldots}$. \\
\hline \multicolumn{2}{|c|}{ 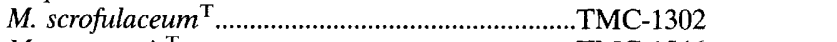 } \\
\hline \multicolumn{2}{|c|}{ 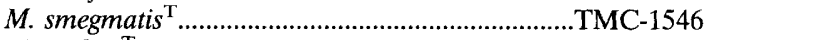 } \\
\hline \multicolumn{2}{|c|}{ 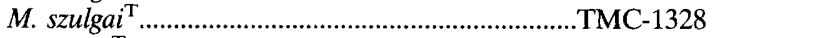 } \\
\hline \multicolumn{2}{|c|}{ 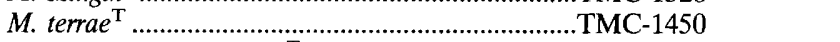 } \\
\hline \multicolumn{2}{|c|}{ 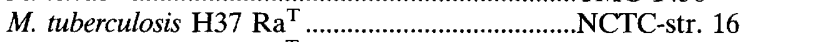 } \\
\hline \multicolumn{2}{|c|}{ M. tuberculosis $\mathrm{H} 37 \mathrm{Rv}^{\mathrm{T}}$........................................... } \\
\hline \multicolumn{2}{|c|}{ 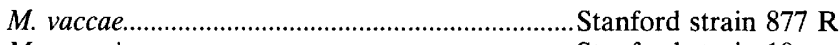 } \\
\hline M. xenopi........................... & Stanford strain 10 \\
\hline M. leprae......................... & Armadillo derived \\
\hline
\end{tabular}

ature and avoiding repeated freezing and thawing. A similar strategy was used to prepare SOD from armadillo liver and spleen and from Escherichia coli.

Measurement of protein concentrations and SOD activity. The protein concentrations in the CEs and the purified SOD enzyme were measured by the method of Lowry et al. (21) and ultraviolet absorption at $280 \mathrm{~nm}$ (17), respectively.

The SOD activity was measured by a spectrophotometric method which is a modification of previously described methods $(11,26)$. In the modified technique, the developed chromogen was not extracted in butanol but was directly assayed at $560 \mathrm{~nm}$ in a UV-visible light spectrophotometer (Shimadzu UV-240) within $2 \mathrm{~h}$. One unit of SOD is defined as the quantity of SOD enzyme required to produce $50 \%$ inhibition of the reduction of Nitro Blue Tetrazolium under specific conditions (8).

PAGE. PAGE was performed as described by Davis (5) and Studier (39). The gels were stained for SOD activity by the method of Beauchamp and Fridovich (1), and for the proteins the staining method of Holbrook and Leaver (9) was used.

Ouchterlony's double diffusion gel technique (27) was used to check the reactivity of the antibodies against purified SOD and to check the cross-reactivity with other bacterial SODs and armadillo SOD from uninfected armadillo liver and spleen.

Raising of antisera. The antisera against different mycobacterial SODs were raised in rabbits by following the strategy of Wayne and Diaz (46). Briefly, a 1-ml mixture consisting of purified SOD $(100 \mu \mathrm{g})$ and immunopeptide adjuvant $(N$ acetyl-muramyl-L-alanyl-D-isoglutamine-muramyl dipeptidase; Sigma) $(1 \mu \mathrm{g}$ in $0.5 \mathrm{ml}$ of $0.01 \mathrm{M}$ phosphate buffer [ $\mathrm{pH} 7.4]$ ) emulsified with an equal volume of incomplete Freund's adjuvant (IFCO/Sigma) was injected intradermally into rabbits. This injection was repeated on the 21 st and 40th days, and the booster was given intravenously without incomplete Freund's adjuvant and immunoadjuvant peptide on the 54th day. The rabbits were bled after 1 week, and the serum was separated and stored in aliquots at $-20^{\circ} \mathrm{C}$. For controls, each rabbit was bled $(10 \mathrm{ml})$ before the injection. Immunoglobulins from each rabbit serum were precipitated by ammonium sulfate and were dissolved in distilled water.

Immunoprecipitation. Immunoprecipitation of SOD with homologous and heterologous antibodies was carried out by a technique standardized previously (13) that was based on the principle of techniques described for catalase (46). In brief, $100 \mu l$ of each serially diluted homologous and heterologous hyperimmune anti-SOD serum was mixed with homologous and heterologous SOD $(1 \mathrm{U})$ and incubated at $37^{\circ} \mathrm{C}$ for $1 \mathrm{~h}$ and then at $4^{\circ} \mathrm{C}$ overnight. The tubes were centrifuged at $8,000 \times g$ for $30 \mathrm{~min}$, and the supernatant was removed without disturbing the sediment. The unbound SODs in the supernatants were estimated, and $50 \%$ endpoints of each titration were then calculated. The rabbit sera collected before immunization were used as controls.

ELISA. Based on the analogous principles of previously described methods (25), the following ELISA procedure was developed for measurement of ImDs of SOD $(33,34)$. A known quantity of antigen $(25 \mu \mathrm{g} / \mathrm{ml})$ was coated on the surface of the microplate wells (Cooke Microtitre) by incubating the plates at $4{ }^{\circ} \mathrm{C}$ overnight after adding $100 \mu \mathrm{l}(2.5 \mu \mathrm{g})$ of purified mycobacterial SOD. The wall surfaces of the wells of the microtiter plates were blocked with $2 \%$ bovine serum albumin fraction $\mathrm{V}$ in phosphate-buffered saline-Tween 20 (PBST). The plates were washed three times for 3 min each with PBST. The wells then received 100 $\mu l$ of serially diluted test rabbit sera (anti-SOD antibodies derived from homologous and heterologous mycobacteria and control rabbit sera) followed by incubation at $37^{\circ} \mathrm{C}$ for $3 \mathrm{~h}$ in a humid chamber. After the plates were washed, 100 $\mu \mathrm{l}$ of diluted $(1: 5,000)$ anti-rabbit immunoglobulins conjugated with horseradish peroxidase in PBST (Dakopatts AB, Alvsjo, Sweden) was added to each well and incubated at $37^{\circ} \mathrm{C}$ for $3 \mathrm{~h}$ or overnight at $4^{\circ} \mathrm{C}$ in an airtight humid chamber. The plates were washed with PBST, $100 \mu l$ of $o$-phenylene diamine in citric acetate buffer ( $\mathrm{pH} 5.0$ ) with $0.03 \% \mathrm{H}_{2} \mathrm{O}_{2}$ (prepared just before use) was added to each well, and the plates were incubated at room temperature in the dark. The reaction was stopped by adding $25 \mu \mathrm{l}$ of $8 \mathrm{~N} \mathrm{H}_{2} \mathrm{SO}_{4}$, and the color was read at $490 \mathrm{~nm}$ in an ELISA Microtitre Reader (model 700, Dynatech Laboratories).

SOD from armadillo liver, spleen, and Escherichia coli were used as controls for the immunodiffusion and other titration studies.

Calculation of ImDs and construction of an evolutionary tree. The proportion of decrease in SOD in the supernatant after precipitation with anti-SOD antibodies (i.e., titers in optical density were plotted on probability graph paper against the log dilution of serum. The binding capacity of serum to a given SOD preparation was the reciprocal of that dilution of serum that will precipitate or bind 1 unit or defined amount of SOD. These were calculated from the points in the titration curve close to the $50 \%$ endpoint on the probability graph $(46,47)$.

ImDs between any two mycobacterial SODs were calculated as follows. The ImD between two heterologous mycobacterial SODs was equal to $100(\log B h-$ $\log B t$ ), where $B h$ is the binding capacity of homologous SOD antigen and antibody and $B t$ is the binding capacity of heterologous SOD antigen and antibody.

The ImDs were then used to construct a tree of evolutionary relatedness by taking into consideration the reciprocal distances between the enzyme-antibody of a particular species and heterologous SOD enzyme-antibody. The basic principle of the technique of Wayne and Diaz $(46,47)$ for construction of an evolutionary tree-based catalase was used for this purpose.

Statistical methods. Correlation of product covariance between ImDs of SOD and published divergences in rRNA as well as dnaJ gene sequences was estimated by using BMDP software (BMDP, Statistical Software Inc., University of California).

\section{RESULTS}

SOD enzyme activity. When the total SOD concentration in the CE was taken as $100 \%$, the yield at the end of purification was found to be approximately $30 \%$. All mycobacterial SODs exhibited single achromatic bands upon PAGE, except for in $M$. chelonei and $M$. phlei SODs, which exhibited two bands. Significant differences in the electrophoretic (eF) values of SOD bands were also found. Overall, rapidly growing mycobacterial SODs exhibited slightly higher eF values than those of slowly growing mycobacteria.

The hyperimmune rabbit sera raised against purified SOD enzymes of different cultivable mycobacterial species were tested against homologous and heterologous SODs and showed precipitate lines by the Ouchterlony double diffusion method. SOD from armadillo liver or spleen and SOD from $E$. coli did not show cross-reactions either with normal rabbit sera or with hyperimmune sera raised against mycobacterial SOD (Fig. 1). The estimated ImDs of all mycobacterial SODs against homologous or heterologous antibodies or vice versa by the immunoprecipitation technique are detailed in Table 2. Similarly, the ImDs between different mycobacterial SODs by the ELISA technique are detailed in the Table 3 . It will be seen that these values were in the same range when determined by either of the techniques. Similar trends were also observed for SOD from $M$. leprae (Table 4).

An evolutionary tree was constructed on the basis of the ImDs between different mycobacterial species used in the study (Fig. 2).

Slowly growing mycobacteria. As estimated by immunoprecipitation (Table 2), the reciprocals of the ImDs between the two strains $M$. tuberculosis $\mathrm{H} 37 \mathrm{Ra}$ and $\mathrm{H} 37 \mathrm{Rv}$ were 4 and 5 ImD units, respectively. The ImDs of $M$. bovis BCG from M. tuberculosis $\mathrm{H} 37 \mathrm{Ra}$ and $\mathrm{H} 37 \mathrm{Rv}$ were slightly greater, i.e., 11 and $15 \mathrm{ImD}$ units, respectively. There were $50 \mathrm{ImD}$ units between the $M$. tuberculosis $\mathrm{H} 37 \mathrm{Ra}$ and $M$. avium, whereas there were $40 \mathrm{ImD}$ units between $M$. avium and $M$. bovis BCG. The ImDs between $M$. tuberculosis $\mathrm{H} 37 \mathrm{Ra}$ and $M$. terrae and $M$. duvalii ( 86 and $84 \mathrm{ImD}$ units, respectively) were almost equal. The ImD between $M$. terrae and $M$. duvalii was 13 units; thus, these species were distinct from each other. A perusal of 


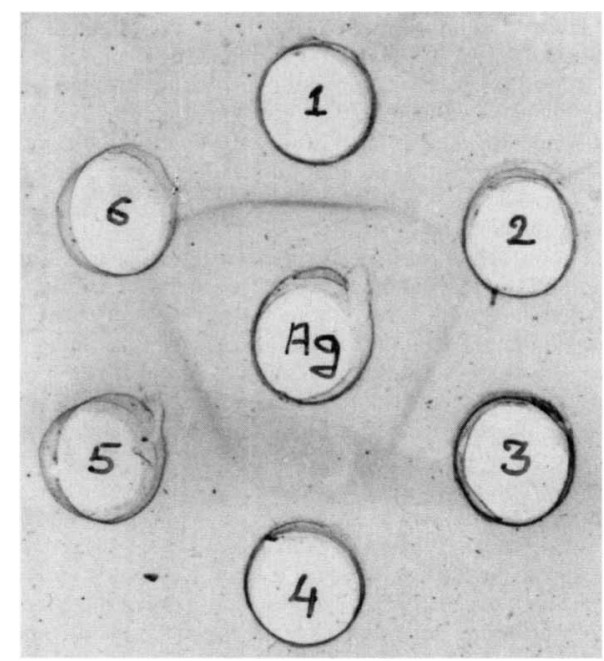

FIG. 1. Ouchterlony double diffusion test showing the cross-reaction among the mycobacterial SOD antigens and antibodies. Ag, SOD antigen from $M$. tuberculosis $\mathrm{H} 37 \mathrm{Ra}$. Other wells contain antibodies to SODs from $M$. tuberculosis H37 Ra (well 1), $M$. xenopi (well 2), $M$. bovis BCG (well 3), $M$. vaccae (well 4), and $M$. smegmatis (well 5) and normal rabbit serum (well 6).

Table 3 shows that trends were similar with the ELISA method.

ImDs of rapidly growing mycobacterial SODs. The distances between rapidly growing mycobacterial SODs were more than $85 \mathrm{ImD}$ units and less than $95 \mathrm{ImD}$ units from $M$. tuberculosis $\mathrm{H} 37 \mathrm{Ra}$ and $\mathrm{Rv}$ and appeared to form a single big cluster. This cluster was, however, nearer to some slowly growing mycobacteria such as $M$. asiaticum and $M$. xenopi, being around $25 \mathrm{ImD}$ units from them. Between $M$. smegmatis and $M$. phlei, the reciprocal $\mathrm{ImD}$ was $21 \mathrm{ImD}$ units, whereas between $M$. vaccae and $M$. phlei it was estimated to be $54 \mathrm{ImD}$ units. $M$. chelonei was between $M$. smegmatis and $M$. vaccae. However, $M$. duvalii was found to be closer to $M$. terrae (a slow grower) on this scale.

ImDs of SOD of $M$. leprae. The ImDs between $M$. leprae and $M$. tuberculosis, $M$. bovis BCG, $M$. avium, $M$. kansasii, and $M$. vaccae were observed to be $30,23,20,39$, and $74 \mathrm{ImD}$ units, respectively, by immunoprecipitation. Similar values $(31,25$, 22,35 , and $75 \mathrm{ImD}$ units) were obtained by the ELISA method. For other mycobacterial species, the distances by immunoprecipitation and ELISA were also in the same range (Table 4).

\section{DISCUSSION}

Cultivable mycobacterial strains grown as either static or shaken cultures yielded sufficient quantities of SODs for their characterization. The purification procedure for SOD was modified from the techniques used earlier $(10,16,18)$. This technique helped in avoiding the lengthy and costly techniques, such as DEAE-cellulose chromatography and Sephadex chromatography, that were used in earlier methods $(10,16,18)$. The presence of SOD in various mycobacteria has been reported by others $(10,18,19,22,48)$. In our study, all mycobacteria showed a single achromatic SOD enzyme band, except for $M$. chelonei and $M$. phlei, which exhibited two clear bands of different mobilities. These differences in electrophoretic mobility were not observed to be taxonomically significant. The procedure of mixing immunoadjuvant peptide with purified SOD plus incomplete Freund's adjuvant, which was described earlier for catalase (46), was also found to be efficient for raising antibodies against mycobacterial SODs.

Serological titrations. ImDs calculated between any two mycobacterial species were found to be reproducible and showed almost similar reciprocal values within a narrow range. While the detection limits were low for ELISA, the ImDs calculated by either of the methods were similar. ELISA, however, would be preferred because of its inherent advantages. Though indi-

TABLE 2. Reciprocal ImDs between different mycobacterial SODs in cultivable mycobacteria as determined by the immunoprecipitation technique

\begin{tabular}{|c|c|c|c|c|c|c|c|c|c|c|c|c|c|c|c|c|}
\hline \multirow[b]{2}{*}{$\begin{array}{l}\text { Mycobacterial } \\
\text { species }\end{array}$} & \multicolumn{16}{|c|}{ ImD of SOD from the following species as determined by immunoprecipitation: } \\
\hline & $\frac{i}{5}$ & 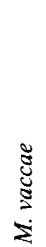 & $\frac{\tilde{\Xi}}{\tilde{\Xi}}$ & 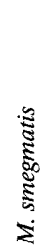 & 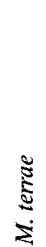 & 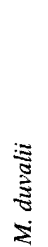 & 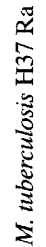 & 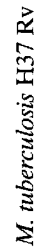 & $\begin{array}{l}0 \\
\mathcal{D} \\
\vdots \\
\vdots \\
\Xi \\
\Sigma \\
\dot{\Sigma}\end{array}$ & 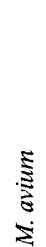 & $\begin{array}{l}\vec{\Xi} \\
\frac{5}{5} \\
\dot{\Sigma}\end{array}$ & 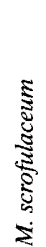 & \begin{tabular}{l}
$\tilde{\Xi}$ \\
\multirow{5}{5}{} \\
$\Sigma$ \\
$\Sigma$
\end{tabular} & 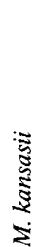 & $\begin{array}{l}\Sigma \\
\vdots \\
\vdots \\
\vdots \\
\Sigma\end{array}$ & 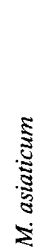 \\
\hline M. phlei & 0 & 54 & 31 & 20 & 58 & 58 & 91 & 92 & 78 & 47 & 34 & 33 & 29 & 45 & 42 & 15 \\
\hline M. vaccae & 55 & 0 & 22 & 45 & 63 & 65 & 94 & 96 & 83 & 51 & 40 & 40 & 34 & 53 & 51 & 25 \\
\hline M. chelonei & 30 & 23 & 0 & 38 & 59 & 62 & 93 & 95 & 76 & 44 & 38 & 35 & 32 & 47 & 49 & 19 \\
\hline M. smegmatis & 21 & 44 & 39 & 0 & 53 & 53 & 89 & 88 & 70 & 44 & 34 & 31 & 25 & 41 & 46 & 12 \\
\hline M. terrae & 59 & 63 & 60 & 54 & 0 & 14 & 86 & 83 & 60 & 31 & 23 & 21 & 28 & 33 & 38 & 21 \\
\hline M. duvalii & 57 & 65 & 61 & 53 & 13 & 0 & 83 & 88 & 65 & 35 & 38 & 23 & 25 & 37 & 39 & 23 \\
\hline M. tuberculosis H37 Ra & 90 & 94 & 92 & 88 & 86 & 84 & 0 & 5 & 15 & 50 & 61 & 80 & 85 & 72 & 74 & 78 \\
\hline M. tuberculosis $\mathrm{H} 37 \mathrm{Rv}$ & 92 & 95 & 92 & 86 & 83 & 87 & 4 & 0 & 11 & 51 & 64 & 81 & 84 & 73 & 75 & 77 \\
\hline M. bovis $\mathrm{BCG}$ & 77 & 82 & 75 & 71 & 58 & 65 & 16 & 12 & 0 & 40 & 49 & 73 & 77 & 59 & 61 & 65 \\
\hline M. avium & 47 & 50 & 45 & 43 & 32 & 35 & 50 & 52 & 42 & 0 & 10 & 11 & 14 & 22 & 24 & 25 \\
\hline M. szulgai & 35 & 42 & 37 & 33 & 23 & 39 & 60 & 63 & 51 & 9 & 0 & 30 & 59 & 15 & 51 & 60 \\
\hline M. scrofulaceum & 33 & 40 & 35 & 31 & 26 & 23 & 80 & 81 & 73 & 11 & 30 & 0 & 51 & 14 & 38 & 31 \\
\hline M. xenopi & 29 & 34 & 32 & 25 & 28 & 25 & 85 & 84 & 77 & 14 & 59 & 53 & 0 & 19 & 41 & 52 \\
\hline M. kansasii & 45 & 53 & 47 & 41 & 53 & 37 & 72 & 73 & 59 & 21 & 15 & 14 & 18 & 0 & 11 & 10 \\
\hline M. gastri & 42 & 51 & 49 & 46 & 38 & 39 & 74 & 75 & 61 & 24 & 51 & 37 & 41 & 10 & 0 & 17 \\
\hline M. asiaticum & 15 & 25 & 19 & 12 & 21 & 23 & 78 & 77 & 65 & 25 & 60 & 31 & 53 & 9 & 15 & 0 \\
\hline
\end{tabular}


TABLE 3. Reciprocal ImDs between different mycobacterial SODs in cultivable mycobacteria as determined by the ELISA technique

\begin{tabular}{|c|c|c|c|c|c|c|c|c|c|c|c|c|c|c|c|c|}
\hline \multirow[b]{2}{*}{$\begin{array}{l}\text { Mycobacterial } \\
\text { species }\end{array}$} & \multicolumn{16}{|c|}{ ImD of SOD from the following species as determined by ELISA: } \\
\hline & $\begin{array}{l}\frac{\widetilde{I}}{\Sigma} \\
\Sigma \\
\Sigma\end{array}$ & 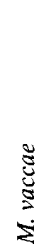 & 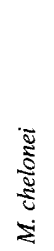 & 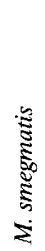 & 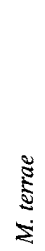 & 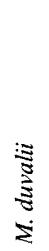 & 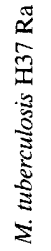 & 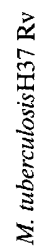 & 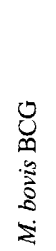 & 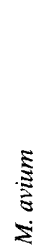 & 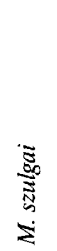 & 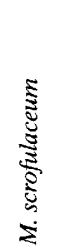 & 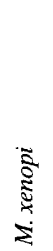 & 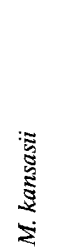 & $\begin{array}{l}5 \\
\text { s. } \\
\text { S } \\
\Sigma\end{array}$ & 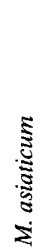 \\
\hline M. phlei & 0 & 52 & 35 & 22 & 57 & 54 & 91 & 92 & 81 & 46 & 35 & 29 & 25 & 45 & 40 & 18 \\
\hline M. vaccae & 51 & 0 & 26 & 44 & 61 & 66 & 93 & 92 & 84 & 52 & 41 & 43 & 35 & 53 & 48 & 26 \\
\hline M. chelonei & 35 & 25 & 0 & 39 & 62 & 63 & 86 & 89 & 78 & 47 & 36 & 33 & 29 & 45 & 48 & 19 \\
\hline M. smegmatis & 21 & 43 & 38 & 0 & 49 & 51 & 82 & 83 & 76 & 42 & 31 & 29 & 23 & 39 & 37 & 11 \\
\hline M. terrae & 57 & 61 & 62 & 49 & 0 & 13 & 85 & 83 & 69 & 34 & 22 & 25 & 29 & 32 & 31 & 20 \\
\hline M. duvalii & 53 & 65 & 63 & 50 & 11 & 0 & 84 & 85 & 63 & 31 & 38 & 23 & 25 & 34 & 37 & 22 \\
\hline M. tuberculosis $\mathrm{H} 37 \mathrm{Ra}$ & 91 & 93 & 86 & 81 & 85 & 82 & 0 & 2 & 11 & 50 & 59 & 83 & 85 & 75 & 80 & 78 \\
\hline M. tuberculosis $\mathrm{H} 37 \mathrm{Rv}$ & 91 & 92 & 89 & 83 & 81 & 85 & 3 & 0 & 14 & 52 & 61 & 85 & 89 & 74 & 79 & 81 \\
\hline M. bovis $\mathrm{BCG}$ & 81 & 85 & 79 & 77 & 69 & 65 & 12 & 13 & 0 & 48 & 53 & 71 & 79 & 63 & 64 & 69 \\
\hline M. avium & 46 & 53 & 47 & 41 & 33 & 31 & 51 & 54 & 47 & 0 & 10 & 14 & 17 & 19 & 23 & 27 \\
\hline M. szulgai & 35 & 42 & 35 & 31 & 22 & 37 & 59 & 62 & 53 & 11 & 0 & 26 & 50 & 17 & 51 & 54 \\
\hline M. scrofulaceum & 29 & 41 & 33 & 29 & 24 & 23 & 83 & 85 & 71 & 13 & 27 & 0 & 53 & 31 & 17 & 30 \\
\hline M. xenopi & 25 & 35 & 29 & 22 & 27 & 23 & 86 & 87 & 79 & 17 & 51 & 53 & 0 & 25 & 41 & 27 \\
\hline M. kansasii & 44 & 54 & 45 & 39 & 29 & 35 & 75 & 74 & 61 & 17 & 14 & 17 & 25 & 0 & 9 & 10 \\
\hline M. gastri & 40 & 49 & 48 & 37 & 35 & 37 & 77 & 79 & 64 & 24 & 51 & 35 & 39 & 8 & 0 & 15 \\
\hline M. asiaticum & 17 & 26 & 18 & 11 & 20 & 21 & 79 & 80 & 67 & 27 & 53 & 31 & 28 & 10 & 16 & 0 \\
\hline
\end{tabular}

cations about qualitative ImDs among the SOD molecules of some mycobacterial species $(10,18,19)$ were suggested earlier and the approach was shown to be promising (14), the present study provides for the first time an easy and convenient ELISA-based procedure for the quantitative measurements of such divergences. Our results and earlier reported findings by Wayne and Diaz (47) further strengthen the confidence in the use of serological measurements for determining the evolutionary relatedness or divergences among mycobacteria.

Construction of an evolutionary tree. On the basis of the estimated reciprocal ImDs among different mycobacterial species, an evolutionary tree was constructed (Fig. 2). M. tubercu-

TABLE 4. ImDs of SOD of M. leprae from cultivable mycobacteria as determined by both the immunoprecipitation technique and the ELISA test

\begin{tabular}{|c|c|c|}
\hline \multirow{2}{*}{$\begin{array}{l}\text { Mycobacterial } \\
\text { species }\end{array}$} & \multicolumn{2}{|c|}{ ImD from SOD of $M$. leprae by ${ }^{a}$ : } \\
\hline & $\begin{array}{c}\text { Immunoprecipitation } \\
\text { technique }\end{array}$ & ELISA test \\
\hline M. phlei & 69 & 71 \\
\hline M. vaccae & 74 & 75 \\
\hline M. chelonei & 64 & 61 \\
\hline M. smegmatis & 61 & 59 \\
\hline M. terrae & 46 & 47 \\
\hline M. duvalii & 56 & 51 \\
\hline M. tuberculosis H37 Ra & 30 & 31 \\
\hline M. tuberculosis H37 Rv & 31 & 29 \\
\hline M. bovis $\mathrm{BCG}$ & 23 & 25 \\
\hline M. avium & 20 & 22 \\
\hline M. szulgai & 29 & 34 \\
\hline M. scrofulaceum & 31 & 38 \\
\hline M. xenopi & 34 & 52 \\
\hline M. kansasii & 39 & 35 \\
\hline M. gastri & 45 & 37 \\
\hline M. asiaticum & 47 & 45 \\
\hline
\end{tabular}

${ }^{a}$ Decimal digits have been rounded up to the nearest whole number. losis $\mathrm{H} 37 \mathrm{Ra}$ was taken as a reference point initially, and all other mycobacteria were placed according to their ImDs from M. tuberculosis $\mathrm{H} 37 \mathrm{Ra}$ and from other mycobacterial ImDs.

Overall, the taxonomic position as shown in the evolutionary tree confirms the validity of previous physiological groupings of mycobacteria into slowly and rapidly growing mycobacteria. However, $M$. terrae, a slowly growing mycobacterium, was
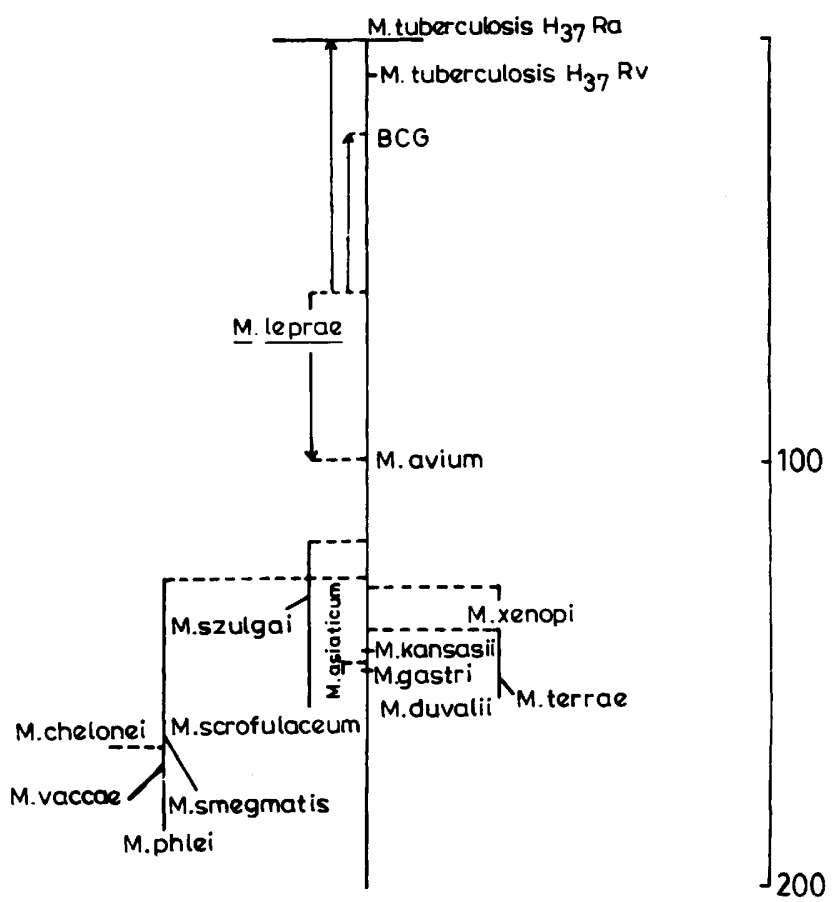

FIG. 2. Evolutionary tree of mycobacteria constructed on the basis of ImDs of their SODs. Percentage differences were doubled to obtain the scale at right. 
TABLE 5. Evolutionary divergencies of mycobacteria from M. avium as determined by SOD ImD, comparative $16 \mathrm{~S}$ rRNA sequencing and dnaJ gene sequence analysis

\begin{tabular}{|c|c|c|c|c|}
\hline \multirow[b]{2}{*}{ Species } & \multicolumn{4}{|c|}{$\%$ Divergence from $M$. avium as determined by ${ }^{a, b}$ : } \\
\hline & $\begin{array}{l}\text { SOD } \\
\text { ImD }\end{array}$ & $\begin{array}{c}\text { 16S rRNA } \\
\text { comparison }(36)\end{array}$ & $\begin{array}{c}\text { 16S rRNA } \\
\text { comparison }(30)\end{array}$ & $\begin{array}{c}\text { dnaJ gene } \\
\text { comparison }(40)\end{array}$ \\
\hline M. tuberculosis & 54 & $\mathrm{ND}^{c}$ & ND & 12 \\
\hline M. bovis & 47 & 1.7 & 20 & 12 \\
\hline M. szulgai & 10 & ND & 15 & 22 \\
\hline M. scrofulaceum & 14 & ND & 22 & 24 \\
\hline M. xenopi & 17 & ND & 63 & 18 \\
\hline M. gastri & 23 & ND & 15 & 25 \\
\hline M. asiaticum & 27 & 1.8 & ND & ND \\
\hline M. kansasii & 19 & 1.2 & 15 & 29 \\
\hline M. terrae & 33 & 3.5 & 48 & ND \\
\hline M. phlei & 46 & 4.6 & ND & ND \\
\hline M. chelonei & 47 & 5.0 & 72 & 33 \\
\hline
\end{tabular}

a Percent divergence for the study by Stahl and Urbance (36); hamming distances for the studies of Rogall et al. (30) and Takewaki et al. (40).

${ }^{b}$ Correlation coefficient between columns 1 and 2, 0.65 ; between columns 1 and $3,0.41$; between columns 3 and 4, 0.24; between columns 1 and 4, -0.33 ; and between columns 2 and $3,0.99$.

${ }^{c} \mathrm{ND}$, not determined.

found to be closely related to $M$. duvalii, a rapidly growing mycobacterial species. The position of $M$. avium in this evolutionary tree was almost in the middle, which is similar to the findings of Wayne and Diaz (47) for catalase. The ImDs among M. scrofulaceum, M. szulgai, and $M$. xenopi and ImDs of each from $M$. tuberculosis have placed them away from $M$. avium and $M$. kansasii. But among themselves (M. scrofulaceum, $M$. szulgai, and $M$. xenopi), the ImDs are quite distinct. Similarly, some branchings were observed, which may be due to mutations leading to the divergences from the main stem of the evolutionary tree. These types of branchings were observed by Wayne and Diaz (47) and by the recent molecular genetic studies based on sequence analysis of rRNA and rRNA genes $(4,28,30,35,36,38,40)$. Estimation of the correlation of product variance between ImDs of SOD, rRNA, and dnaJ gene divergencies shows interesting results. Even though the number of species is not sufficient for statistical evaluation, moderate correlation between ImDs of SOD and rRNA divergencies $(30,36)$ was observed. On the other hand, correlation was low between SOD ImDs and dnaJ gene sequence analysis (40) and between 16S rRNA (30) and dnaJ gene (40) sequence analysis (Table 5). In this analysis, $M$. avium was taken as a reference point. Such analysis has limited value at present, as many of the strains selected for these investigations were also different in these studies. Clearly, more comparative studies are necessary to understand this aspect further, especially when the relationships are to be quantified. Catalase and SODs are thus additional molecules with which to study the evolutionary divergences.

Compared to biochemical characterization and conventional serological, bacteriophage, and bacteriocin typing, our approach has the major advantage of applicability to tissue-derived pathogens, as observed with $M$. lepraemurium earlier (12) and with $M$. leprae in the present study. This approach could be useful for studying other host-grown and difficult-to-grow organisms, including mycobacteria (7).

Our system also confirms the position of $M$. leprae in the mycobacterial phylogenetic tree already determined by using the rRNA genes as markers $(4,30)$ and may be used as a new reference system for determining the taxonomic and/or phylogenetic relationships among mycobacteria. Along with the emerging gene probes, such techniques would provide reliable additional techniques for this purpose. Even though the concept of this approach is old, it appears to be quite relevant even now.

Divergences of the SOD molecule of $M$. leprae show that the reactivity to the specific epitopes on this molecule has the potential for development of immunoassays for diagnostic and prognostic purposes. Since the present seroassays have the major disadvantages of persistence of antigens and resultant antibodies, it could be an attractive serological approach (14). If this strategy succeeds, such relevant epitopes can be generated by synthetic chemistry or recombinant DNA technologies, as the SOD genes have already been cloned in $M$. leprae and M. tuberculosis $(42,49)$.

\section{ACKNOWLEDGMENTS}

The authors are thankful to L. G. Wayne for valuable discussions of this study during his visit to this institute; to Noel S. Singh, S. K. Bhan, Shri Ram, and A. Robi for technical help; to H. O. Agrawal and N. Dubey for illustrations; and to J. D. Kushwah for secretarial assistance. The gift of some reagents by LEPRA, U.K., is gratefully acknowledged.

\section{REFERENCES}

1. Beauchamp, C., and I. Fridovich. 1971. Superoxide dismutase: improved assay and an assay applicable to acrylamide gels. Anal. Biochem. 44:276-287.

2. Chikata, Y., E. Kusunose, K. Ichihara, and M. Kusunose. 1975. Purification of superoxide dismutase from $M$. phlei. Osaka City Med. J. 21:127-136.

3. Cocks, G. T., and A. C. Wilson. 1969. Immunological detection of single amino-acid substitutions in alkaline phosphatase. Science 164:188-189.

4. Cox, R. A., K. Kempsell, L. Fairclough, and M. J. Colston. 1991. The 16S ribosomal RNA of Mycobacterium leprae contains a unique sequence which can be used for identification by polymerase chain reaction. J. Med. Microbiol. 35:284-290.

5. Davis, B. J. 1964. Disc electrophoresis methods and application to human serum protein. Ann. N. Y. Acad. Sci. 121:404-427.

6. Draper, P. 1980. Protocol for purification of M. leprae. In WHO document no. TDR/IMMLEP-SWG (5)/80.3.

7. Feldman, R. A., and E. Hershfield. 1974. Mycobacterial skin infections by an unidentified species: a report of 27 patients. Ann. Intern. Med. 80:445-452.

8. Fridovich, I. 1974. Superoxide dismutases. Adv. Enzymol. 41:35-97.

9. Holbrook, I. B., and A. G. Leaver. 1976. A procedure to increase the sensitivity of staining by Coomassie Brilliant Blue G-250 perchloric acid solution. Anal. Biochem. 75:634-636.

10. Ichihara, K., E. Kusunose, M. Kasunose, and T. Mori. 1977. Superoxide dismutase from Mycobacterium lepraemurium. J. Biochem. 81:1427-1433.

11. Kakkar, P., B. Das, and P. N. Vishwanathan. 1984. A modified spectrophotometric assay of superoxide dismutase. Indian J. Biochem. Biophys. 21:130143.

12. Katoch, V. M., C. T. Shivannavar, and A. K. Datta. 1989. Studies on ribosomal RNA genes of mycobacteria including M. leprae. Acta. Leprol. 7 (Suppl. 1):231-233.

13. Katoch, V. M., C. T. Shivannavar, A. K. Datta, and V. D. Sharma. 1987. The evaluation of immunological relatedness of superoxide dismutase in taxonomic identification. Indian J. Med. Microbiol. 5:17-24.

14. Katoch, V. M., L. G. Wayne, and G. A. Diaz. 1982. Characterization of catalase by micro-immunoprecipitation in tissue derived cells of Mycobacte. rium lepraemurium TMC 1701. Int. J. Syst. Bacteriol. 32:416-418.

15. Katoch, V. M., L. G. Wayne, and G. A. Diaz. 1982. Serological approaches for the characterization of catalase in tissue derived Mycobacterium leprae. Ann. Inst. Pasteur Microbiol. 133B:407-414.

16. Keele, B. B., Jr., J. M. McCord, and I. Fridovich. 1970. Superoxide dismutase from Escherichia coli B. A new manganese-containing enzyme. J. Biol. Chem. 245:6176-6181.

17. Kirschenbaum, D. M. 1977 . Molar absorptivity and $A 1 \%$ values for protein of selected wavelengths of the ultraviolet and visible regions. Anal. Biochem. 82:83-100.

18. Kusunose, E., K. Ichihara, Y. Nada, and M. Kusunose. 1976. Superoxide dismutase from Mycobacterium tuberculosis. J. Bacteriol. 80:1342-1352.

19. Kusunose, E., M. Kusunose, K. Ichihara, and S. Izumi. 1981. Superoxide dismutase in cell-free extracts from $M$. leprae grown in armadillo liver. FEMS Microbiol. Lett. 10:49-52.

20. Loewenstein, E. 1930. Die Methodik der Reinkultur von tuberkelbacillen aus dem Blute. Dtsch. Med. Wochenschr, 56:1010.

21. Lowry, O. H., N. J. Rosebrough, A. L. Farr, and R. J. Randall. 1951. Protein measurement with the folin phenol reagent. J. Biol. Chem. 193:265-275. 
22. Mayer, B. K., and J. O. Falkinham III. 1986. Superoxide dismutase activity of Mycobacterium avium, $M$. intracellulare, and $M$. scrofulaceum. Infect. Immun. 53:631-635.

23. McFadden, J. J. 1990. DNA probes for detection and identification, p 139-172. In J. J. McFadden (ed.), Molecular biology of mycobacteria. Surrey University Press, Academic Press, London.

24. Minnikin, D. E., and M. Goodfellow. 1980. Lipid composition in classification and identification of acid-fast bacteria, p. 184-256. In M. Goodfellow and R. G. Board (ed.), Microbiological classification and identification. Academic Press, London.

25. Nader de Macias, M. E., G. Perdigon, G. Oliver, and A. E. Holgado. 1986 Enzyme-linked immunosorbent assay (ELISA) for determining immunological relationships among $\beta$-galactosidases from lactobacilli. Syst. Appl. Microbiol. 8:28-31.

26. Nishikimi, M., N. A. Rao, and K. Yogi. 1972. The occurrence of superoxide anion in the reduction of reduced phenazine methosulphate and molecular oxygen. Biochem. Biophys. Res. Commun. 46:849-854.

27. Ouchterlony, O. 1949. Antigen-antibody reactions in gels. Acta Pathol. Microbiol. Scand. 25:186-191.

28. Pitulle, C., M. Dorsch, J. Kazda, J. Wolters, and E. Stackebrandt. Phylogeny of rapidly growing members of genus Mycobacterium. Int. J. Syst. Bacteriol. 42:337-343.

29. Rado, T. A., J. H. Bates, H. W. S. Engel, E. Manckicwicz, I. Murohashi, Y. Mizuguchi, and L. Sula. 1975. World Health Organization studies on bacteriophage typing of mycobacteria. Subdivision of species M. tuberculosis. Am. Rev. Respir. Dis. 111:459-468.

30. Rogall, T., J. Wolters, T. Flohr, and E. Böttger. 1990. Towards a phylogeny and definition of species at the molecular level within the genus Mycobacterium. Int. J. Syst. Bacteriol. 40:323-330.

31. Sauton, B. 1912. Sur la nutrition minérale du bacille tuberculeux. C. R. Acad. Sci. 155:860.

32. Schaefer, W. B. 1967. Scrological classification of atypical mycobacteria and its value in epidemiological studies. Am. Rev. Respir. Dis. 96:1165-1168.

33. Shivannavar, C. T. 1993. Studies on the immunological relatedness of superoxide dismutases of mycobacteria. Ph.D. thesis. Agra University, Agra, India.

34. Shivannavar, C. T., V. M. Katoch, V. D. Sharma, M. A. Patil, K. Katoch, V. P. Bharadwaj, and B. M. Agrawal. 1996. Development of a superoxide dismutase (SOD) based enzyme linked immunosorbent assay (ELISA) to determine the immunological relatedness among mycobacteria. Int. J. Lepr., in press.

35. Smida, J., J. Kazda, and E. Stackebrandt. 1988. Molecular genetic evidence for the relationship of Mycobacterium leprae to slow growing pathogenic mycobacteria. Int. J. Lepr. 56:449-454.

36. Stahl, D. A., and J. W. Urbance. 1990. The division between fast- and slow-growing species corresponds to natural relationships among the mycobacteria. J. Bacteriol. 172:116-124.

37. Stanford, J. L., and J. M. Grange. 1974. The meaning and structure of species as applied to mycobacteria. Tubercle 55:143-152.

38. Stone, B. B., R. M. Nietupski, G. L. Breton, and W. G. Weisburg. 1995. Comparison of mycobacterium 23S rRNA sequences by high-temperature reverse transcription and PCR. Int. J. Syst. Bacteriol. 45:811-819.

39. Studier, F. W. 1973. Analysis of bacteriophage T7 early RNAs and proteins on slab gels. J. Mol. Biol. 79:237-248.

40. Takewaki, S. I., K. Okuzumi, I. Manabe, M. Tanimura, K. Miyamura, K. Nakahara, Y. Yazaki, A. Ohkubo, and R. Nagai. 1994. Nucleotide sequence comparison of mycobacterial dnaJ gene and PCR-restriction fragment length polymorphism analysis for identification of mycobacterial species. Int. J. Syst. Bacteriol. 44:159-166.

41. Takeya, K., and H. Tokiwa. 1972. Mycobacteriocin classification of rapidly growing mycobacteria. Int. J. Syst. Bacteriol. 22:178-180.

42. Thangaraj, H. S., F. I. Lamb, E. O. Davi, P. J. Jenner, L. H. Jeyerkur, and M. J. Colston. 1990. Identification, sequencing and expression of Mycobacterium leprae superoxide dismutase, a major antigen. Infect. Immun. 58: 1937-1942.

43. Tsukamura, M. 1967. Identification of mycobacteria. Tubercle 48:311-338.

44. Wayne, L. G., et al. 1974. Highly reproducible techniques for use in systematic bacteriology in the genus Mycobacterium: tests for pigment, urease, resistance to sodium chloride, hydrolysis of Tween 80 , and $\beta$-galactosidase. Int. J. Syst. Bacteriol. 24:412-419.

45. Wayne, L. G., et al. 1976. Highly reproducible techniques for use in systematic bacteriology in the genus Mycobacterium: tests for niacin and catalase and for resistance to isoniazide, thiophene 2-carboxylic acid hydrazide, hydroxylamine, and $p$-nitrobenzoate. Int. J. Syst. Bacteriol. 26:311-318.

46. Wayne, L. G., and G. A. Diaz. 1976. Immunoprecipitation studies of mycobacterial catalase. Int. J. Syst. Bacteriol. 26:38-44.

47. Wayne, L. G., and G. A. Diaz. 1979. Reciprocal immunological distances of catalase derived from strains of Mycobacterium avium, Mycobacterium tuberculosis, and closely related species. Int. J. Syst. Bacteriol. 29:19-34.

48. Wheeler, P. R., and D. Gregory. 1980. Superoxide dismutase, peroxidatic activity and catalase in Mycobacterium leprae purified from armadillo liver. J. Gen. Microbiol. 121:457-464.

49. Zhang, Y., R. Lathigra, T. Garbe, D. Catty, and D. Young. 1991. Genetic analysis of superoxide dismutase, the 23-kilodalton antigen of Mycobacterium tuberculosis. Mol. Microbiol. 5:381-391. 